\title{
Improved tumour localisation using indium-111 labelled antibodies
}

\author{
D S FAIRWEATHER, A R BRADWELL, P W DYKES, A T VAUGHAN, S F WATSON-JAMES, \\ $S$ CHANDLER
}

\begin{abstract}
Immunoglobulin $\mathrm{G}$ (IgG) antibodies to carcinoembryonic antigen (CEA) were labelled with radioactive indium ( ${ }^{111}$ In) or iodine $\left.{ }^{131} I\right)$ and a comparison made of their value in locating CEA producing tumours. Eleven patients given ${ }^{111}$ In-anti-CEA had 31 tumours as judged by a combination of all techniques. Of these, 28 were detected by ${ }^{111}$ In-anti-CEA and 26 by conventional clinical techniques. Five of the patients also received ${ }^{131}$ I-antiCEA. These patients had 15 tumour areas. Thirteen were detected by ${ }^{11}$ In and eight by ${ }^{131} I$. ${ }^{111}$ In also produced a better signal to noise ratio in the scans and thereby showed lesions with greater certainty. In addition, the ${ }^{11}$ In isotope continued to accumulate in the tumour areas for considerably longer than ${ }^{131} I$.

Absorbed doses (whole body) were similar for both isotopes. The results show that antibody scanning is greatly improved by using ${ }^{111}$ In as the radiolabel in place of ${ }^{131} I$ and should allow the detection of smaller or deeper lesions.
\end{abstract}

\section{Introduction}

There is considerable interest in the localisation of tumours using radiolabelled antibodies. Tumours of the gastrointestinal

\footnotetext{
Department of Immunology, University of Birmingham, Birmingham B15 2TJ

D S FAIRWEATHER, BA, MRCP, honorary senior medical registrar A R BRADWELL, MRCP, MRCPATH, senior lecturer

P W DYKES, MD, FRCP, consultant physician

A T VAUGHAN, PHD, lecturer

S F WATSON-JAMES, BSC, technician

Department of Nuclear Medicine, Queen Elizabeth Hospital, Birmingham B15 2TH

S CHANDLER, MSC, senior physicist

Correspondence to: Dr A R Bradwell, Department of Immunology, Medical School, University of Birmingham, Birmingham B15 2TJ.
}

tract, ${ }^{1}$ thyroid, ${ }^{2}$ germ cell tissue,,$^{34}$ and insulinomas ${ }^{5}$ have been detected using various different antibodies. In most reports iodine-131 ( $\left.{ }^{131} \mathrm{I}\right)$ has been used as the radiolabel, but it is not ideal because the high energy gamma ray is poorly detected and the emission of $\beta^{-}$contributes to a high radiation dose. ${ }^{123}$ I has been tried ${ }^{6}$ but has a short half life (13 hours) and cannot be used in a dual isotope procedure with technetium- $99 \mathrm{~m}$ $\left({ }^{99 \mathrm{~m}} \mathrm{Tc}\right)$ for background subtraction. Two further problems with iodine isotopes are that they are not retained in cells and iodination of proteins is too time consuming for a nuclear medicine department.

Indium-111 ( $\left.{ }^{111} \mathrm{In}\right)$ has been suggested ${ }^{7}$ as an alternative radiolabel for the following reasons: (a) the gamma energies (171 and $247 \mathrm{keV}$ ) are better detected by conventional gammacameras; $(b)$ the half life ( 2.83 days) is more suitable for antibody imaging; $(c)$ it is known to be chemically stable within cells ${ }^{8}$; and $(d)$ protein labelling can be conveniently and simply carried out using a bifunctional chelating agent. ${ }^{9}$ Disadvantages of using ${ }^{111} \mathrm{In}$ are, firstly, that the available isotope has a lower effective specific activity than iodine and, secondly, that it is complex to prepare chelate linked proteins with enough groups available to bind ${ }^{11}$ In in large amounts. A chelate that has been used for ${ }^{111}$ In binding is diethylenetriamine-penta-acetic acid (DTPA), which has been successfully linked to albumin ${ }^{10}$ for use as a blood pool reagent and to anti-myosin ${ }^{11}$ for imaging canine myocardium. Recently a monoclonal antibody to carcinoembryonic antigen (CEA) radiolabelled with ${ }^{111}$ In via DTPA has been shown successfully to localise to human tumours transplanted into nude mice. ${ }^{12}$

We describe the preparation and labelling of an antiserum to CEA with ${ }^{11}$ In to high specific activity and its use for locating tumours in 11 patients. Five of the patients were also scanned using the same antibody labelled with ${ }^{131} \mathrm{I}$.

\section{Methods and patients}

ANTISERUM

Polyclonal antiserum to CEA was prepared in sheep by immunising with CEA extracted from hepatic metastases of a colonic carcinoma. Non-specific antibodies were adsorbed on glutaraldehyde polymers of 
human serum and normal tissues until a specific reaction was obtained on colorectal carcinoma tissue sections using the peroxidase antiperoxidase technique. A fraction of the antiserum rich in immunoglobulin G (IgG) was prepared by ion exchange chromatography on diethylaminoethyl (DEAE) 52 cellulose, then sterilised by filtration and tested for pyrogens by an independent laboratory. Both before and after radiolabelling, the titre of the antibody was tested by reverse radial immunodiffusion. Affinity was assessed by a double antibody radioimmunoassay using ${ }^{125}$ I labelled CEA. ${ }^{13}$ For this the antibody was labelled with ${ }^{113 \mathrm{~m} I n}$ (obtained from a tin-113 generator) rather than ${ }^{111} I n .{ }^{125} I$ counts were corrected for the contribution from ${ }^{131} I$ by repeat counting after one month.

\section{RADIOLABELLING}

${ }^{111}$ In labelling

DTPA was first linked to the antiserum using the method of Krejcarek and Tucker ${ }^{14}$ to substitute up to three molecules of DTPA per antibody molecule in order to achieve a comparable specific activity with the iodinated antibody. Aliquots of $800 \mu \mathrm{l}$ (as $0.5 \mathrm{ml}$ in $0.01 \mathrm{M}$ sodium acetate buffer, $\mathrm{pH} 6.0$ ) were freeze dried and stored at $-70^{\circ} \mathrm{C} .{ }^{111}$ In (INS I; Amersham International) supplied as indium chloride (in $0.04 \mathrm{M} \mathrm{HCl}$ ) was first neutralised with sodium acetate buffer (to $\mathrm{pH} 6 \cdot 0-6 \cdot 5)$ containing acetate $0.3 \mathrm{~mol} / \mathrm{l}$, then $550 \mu \mathrm{l}(74$ $\mathrm{MBq} ; 2.0 \mathrm{mCi}$ ) was added to the antibody, mixed, and allowed to react at $4^{\circ} \mathrm{C}$ for 12 hours. Unbound ${ }^{111}$ In was separated on a $10 \mathrm{ml}$ Sephadex G25 column (PD 10, Pharmacia, GB).

For use in patients, after the material had been eluted from the G25 column $1 \mathrm{ml} \mathrm{10 \%}$ human albumin (Blood Products Laboratory, Elstree) and $10 \mathrm{mg}$ disodium edetic acid (EDTA) were added. The latter ensured that ${ }^{111}$ In released from the antibody before injection would be chelated and rapidly excreted in the urine. The overall labelling efficiency was assessed by counting the final product in a calibrated well counter (Pitman Medical, Weybridge) and comparing the recovered activity with that in the starting material. Fractions of the material were further tested for non-specific binding: ${ }^{111}$ In bound to free DTPA was assessed by separation from the ${ }^{111}$ In DTPA protein complex on a $6 \times 250 \mathrm{~mm}$ Sephadex G75 column. Also any ${ }^{111}$ In non-specifically bound to IgG-that is, not via DTPA - was determined by lowering the $\mathrm{pH}$ to 3.0 (when it becomes unbound) and precipitating the IgG with saturated ammonium sulphate.

\section{${ }^{131}$ I labelling}

${ }^{131}$ I labelling was carried out as described ${ }^{15}$ to substitute one atom of iodine per antibody molecule.

\section{NUCLEAR MEDICINE TECHNIQUES}

\section{Dosimetry}

Whole body and specific organ doses from administered radionuclides were calculated using the MIRD tables of the Society of Nuclear Medicine. ${ }^{16}$ Isotope excretion rates were measured by counting 24 hour urine samples in four patients for each isotope. Organ uptakes were calculated from the gammacamera scans taken in three projections. ${ }^{17}$ Dose to the urinary bladder was calculated from the urinary excretion rates. For a best case we assumed that the 24 hour urine volume was 2 litres and the bladder emptied frequently. For the worst case we assumed a urine volume of 1 litre and an emptying frequency of eight hours.

\section{Scanning procedures}

Patients were injected with 18.5 to $66.0 \mathrm{MBq}(0.5$ to $1.8 \mathrm{mCi})$ of either ${ }^{131} \mathrm{I}$-anti-CEA or ${ }^{111}$ In-anti-CEA. Patients scanned with both isotopes received the same dose on each occasion. Whole body scintigrams were taken 24 hours later and at various times up to nine days after injection. All scans were obtained with a Searle LFOV gammacamera linked to a DEC PDP $11 / 40$ computer. A high energy $(410 \mathrm{keV})$ parallel hole collimator was used for the ${ }^{131} \mathrm{I}$ emission scans, and a medium energy $(280 \mathrm{keV})$ collimator for the ${ }^{111} \mathrm{In}$ scans. Count times were five minutes per view for both isotopes. Two background subtraction techniques were used:
(1) Up to 48 hours after injection activities in blood pool and extravascular space were subtracted by the use of ${ }^{99} \mathrm{~m} \mathrm{Tc}$-pertechnetate $(18.5 \mathrm{MBq} ; 0.5 \mathrm{mCi})$ and ${ }^{99} \mathrm{mTc}$-albumin $(18.5 \mathrm{MBq})$ injected 30 and five minutes respectively before each scan. Normalisation of the two emissions were made over the heart or a specific area of interest and $c$ the ${ }^{99 \mathrm{~m} T c}$ image subtracted pixel by pixel from the antibody image.

(2) With ${ }^{111}$ In scans after 48 hours subtraction was used only if $\bar{\Xi}$ hepatic metastases were suspected, in which case ${ }^{99 \mathrm{~m}} \mathrm{Tc}$-colloid (37 70 $\mathrm{MBq} ; 1.0 \mathrm{mCi}$ ) was injected and normalisation carried out over the $\mathbb{D}$ liver.

The subtraction scan was displayed in two forms-firstly, simply $\stackrel{?}{?}$ as calculated and, secondly, by using a threshold to display only $\Rightarrow$ significant counts. This threshold was obtained by calculating the $\stackrel{\vec{O}}{\rightarrow}$ variance in the scan due to random fluctuations in the background $\overline{0}$ and subtracting two standard deviations from each pixel. This gives an indication of the relative significance of counts left in the sub- $\overline{\bar{\omega}}$ traction picture. These counts were regarded as representing possible $\vec{\nabla}$ sites of tumour if they did not correspond to known sites of accumulation of isotope.

The scans were assessed visually and each tumour site scored as ++ if the "thresholded" subtraction scan was positive or the area. was seen in all views on two occasions, + if the area was seen on one view on two occasions or two views on one occasion, or negative $(-)$.

\section{PATIENTS}

Eleven patients with raised serum concentrations of CEA were $\dot{\mathcal{E}}$ studied. Eight had colorectal tumours, one a squamous carcinoma of $\infty$ the lung, one a laryngeal carcinoma, and one a medullary thyroid $\vec{\overrightarrow{ }}$ carcinoma. Patients were staged by conventional clinical techniques $\vec{\gamma}$ (excluding computed tomography) and by laparotomy in some cases. $\bigcirc$ All received $1 \mathrm{~g}$ potassium perchlorate two hours before each injection of the ${ }^{99 \mathrm{~m}} \mathrm{Tc}$ pharmaceuticals. In addition, patients given ${ }^{131} \mathrm{I}$-anti- $\vec{\sigma}$ CEA received potassium iodide $180 \mathrm{mg} /$ day for one week. Where $\overleftarrow{c}$ practicable, patients were studied with both antibodies. Injection of $\stackrel{一}{\gtrless}$ antiserum was made after an intravenous test dose to exclude ana- $\vec{\bullet}$ phylactic hypersensitivity to sheep protein. All gave informed consent.

\section{Results}

\section{PATIENTS}

In the 11 patients a total of 31 potentially tumour containing "areas" were detected by various clinical and radiological techniques (table I). Nine were in the head and neck, five in the chest, seven in the liver, and $\exists$ the remaining 10 at various other sites in the abdomen and pelvis. Twenty eight areas were positive on the ${ }^{111}$ In scan and 26 were confirmable by conventional clinical techniques.

Five patients had both ${ }^{131} \mathrm{I}$ scans and ${ }^{111}$ In scans (table I). These patients had 15 tumour areas, 13 of which were positive by ${ }^{11}$ In and eight by ${ }^{131} \mathrm{I}$. There was thus an excess of five sites in the ${ }^{111}$ In group, but in only two of these could tumour be confirmed.

The figures in table I represent accumulative results from several $\delta$ views for each patient. To compare individual ${ }^{111}$ In scans with ${ }^{131} \mathrm{I}$ scans they were matched for time since injection and anatomical 은 projection. There were 23 such pairs; in the ${ }^{111}$ In group 18 were positive on the thresholded subtraction scan $(++)$ compared with $\mathbb{N}$ eight in the ${ }^{131} I$ group.

Figure 1 shows the unsubtracted right lateral views of the head and neck of one patient with a secondary squamous carcinoma deposit in $\overline{\mathrm{N}}$ the area of the right temporomandibular joint. The count rate was too low for the tumour to be visualised beyond two days with ${ }^{131} \mathrm{I} \omega$

TABLE I-Antibody scan results

\begin{tabular}{|c|c|c|c|c|c|c|c|c|}
\hline \multirow{2}{*}{\multicolumn{3}{|c|}{$\begin{array}{l}{ }^{111} \text { In scans in } 11 \text { patients } \\
\text { (No of tumour "areas" }=31)\end{array}$}} & \multicolumn{6}{|c|}{$\begin{array}{l}\text { Comparison of scans in } 5 \text {, patients } \\
(\text { No of tumour "areas" }=15)\end{array}$} \\
\hline & & & \multicolumn{3}{|c|}{${ }^{111} \mathrm{In}$} & \multicolumn{3}{|c|}{${ }^{131} \mathrm{I}$} \\
\hline $\begin{array}{r}+ \\
+ \\
+\end{array}$ & $\begin{array}{r}18 \\
10 \\
3\end{array}$ & $\begin{array}{c}(16)^{*} \\
(7) \\
(3)\end{array}$ & $\begin{array}{r}+ \\
+ \\
+\end{array}$ & $\begin{array}{r}10 \\
3 \\
2\end{array}$ & $\begin{array}{l}(8)^{*} \\
(1) \\
(2)\end{array}$ & $\begin{array}{r}++ \\
+ \\
+\end{array}$ & $\begin{array}{l}4 \\
4 \\
7\end{array}$ & $\begin{array}{l}(4)^{*} \\
(4) \\
(2)\end{array}$ \\
\hline
\end{tabular}

* Figures in parentheses are numbers of sites definitely confirmed by other tests. $++=$ Highly significant result-subtraction scan above threshold value or area

$+=$ Significant result - area seen on the view on two occasions or two views on one

- Negative result. 
and subtraction was necessary to enhance the image. In contrast, ${ }^{111}$ In gave a clear, positive scan five days after injection (fig $1(c)$ ), and at nine days the tumour was still visible without subtraction. Table II gives the ratios of tumour to normal tissue for these scans, and even when these ratios were equal (day 1) the ${ }^{111}$ In scan was visually superior, as assessed by the count rate per pixel in the tumour (table II). In the example in table II the subtraction scans with the ${ }^{131}$ I antibody contained 100 counts at 24 hours and 189 counts at 48 hours over the whole tumour $(2 \cdot 2$ and $5 \cdot 2$ standard deviations respectively above the background counting error). In the ${ }^{111}$ In subtraction image the count rates were 226 at 24 hours and 825 at 48 hours-that is, 2.6 and $10 \cdot 6$ standard deviations respectively above the background counting error.
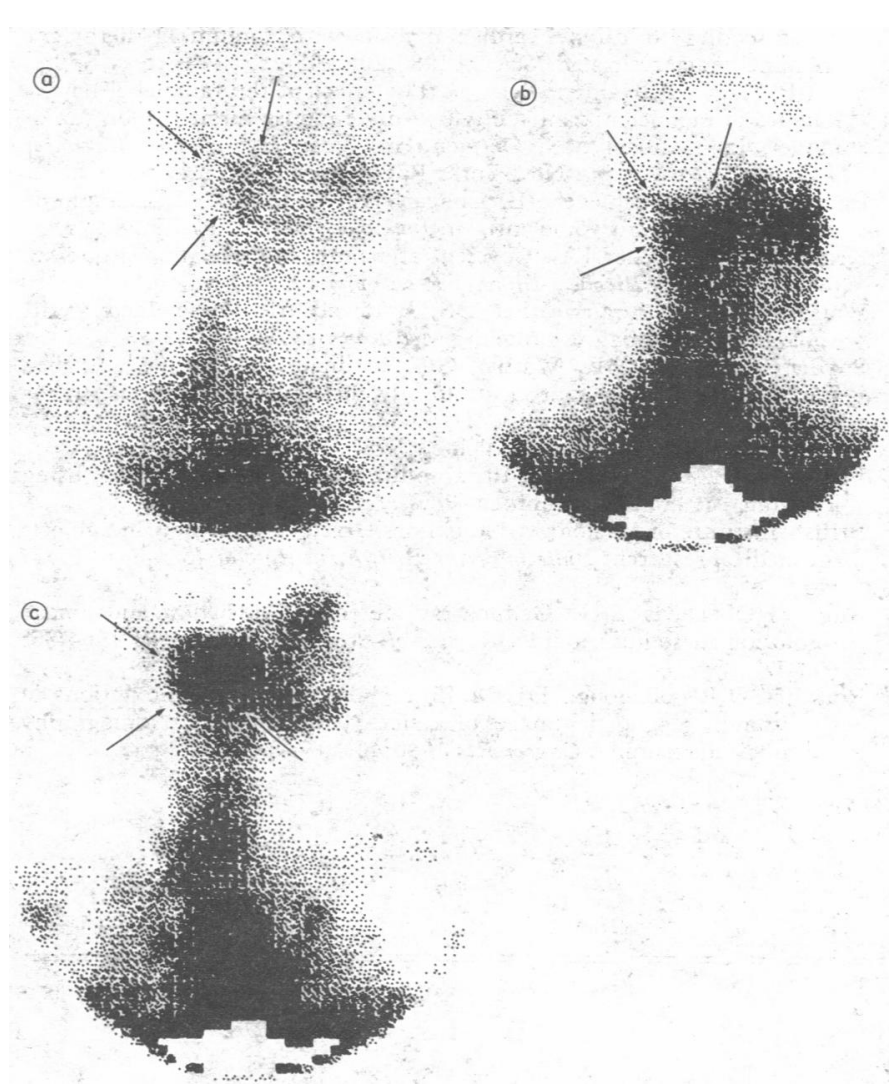

FIG 1-Unsubtracted lateral view of head and neck in patient with squamous carcinoma in region of right temporomandibular joint. (a) ${ }^{131} \mathrm{I}$-anti-carcinoembryonic antigen (CEA) 24 hours after injection. (b) ${ }^{111}$ In-anti-CEA at 24 hours after injection. (c) ${ }^{111} \mathrm{In}$-anti-CEA five days after injection.

TABLE II-Count rates from scans of one patient given ${ }^{111}$ In and ${ }^{131} I$ labelled antibody

\begin{tabular}{|c|c|c|c|c|c|}
\hline & & \multicolumn{4}{|c|}{ Days after antibody injection } \\
\hline & & 1 & 2 & 5 & 9 \\
\hline $\begin{array}{l}\text { Ratio of tumour } \\
\text { to normal tissue }\end{array}$ & $\left\{\begin{array}{l}111 \mathrm{In} \\
{ }^{1: 31} \mathrm{I}\end{array}\right.$ & $\begin{array}{l}2 \cdot 1 \\
2 \cdot 1\end{array}$ & $\begin{array}{l}2 \cdot 7 \\
1 \cdot 9\end{array}$ & $\begin{array}{l}3 \cdot 1 \\
*\end{array}$ & $1 \cdot 8$ \\
\hline Counts/min/pixel & $\left\{\begin{array}{l}{ }^{111} \text { In } \\
{ }^{1 \cdots 1} I\end{array}\right.$ & $\begin{array}{c}25 \cdot 4 \\
9 \cdot 2\end{array}(25 \cdot 4) \dagger$ & $\underset{7 \cdot 0}{24 \cdot 1}$ & $11(29 \cdot 3)$ & $7 \cdot 4_{+}^{+}(21 \cdot 5)$ \\
\hline
\end{tabular}

*Not scanned.

tCounts in parentheses corrected for physical decay.

${ }_{+}$Both ${ }^{111}$ In photopeaks counted.

\section{RADIOLABELLING OF ANTIBODY}

Radiolabelling with ${ }^{111}$ In had an overall efficiency of $50-75 \%$ giving a maximum specific activity of $74 \mathrm{MBq}(2.0 \mathrm{mCi}) / \mathrm{mg}$ protein. After separation on a G25 column, $100 \%$ of the counts were shown to be protein bound by filtration on Sephadex G75 and $90^{\circ}$ o precipitable by saturated ammonium sulphate at $\mathrm{pH} 3.0$.

Overall titre of the antiserum, as assessed by reverse radial immuno- diffusion, was unaffected by either ${ }^{111}$ In or ${ }^{131}$ I labelling, but the binding assay showed a reduction in high affinity binding sites in the DTPA linked antiserum (fig 2).

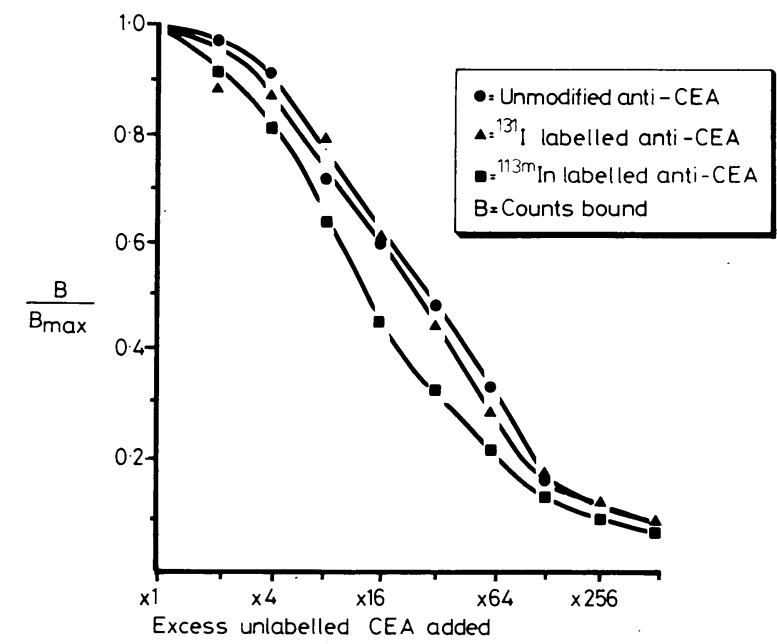

FIG 2-Binding of ${ }^{125} \mathrm{I}$-carcinoembryonic antigen (CEA) to unmodified and radiolabelled anti-CEA. Each point is mean of three experiments for each antibody. Range of each value about $6 \%$ for unmodified and ${ }^{113 \mathrm{~m}}$ In labelled antibody and $9 \%$ for ${ }^{131}$ I labelled antibody.

\section{DISTRIBUTION AND DOSIMETRY OF LABELLED ANTIBODIES}

In the first 24 hours after injection $33 \%$ (range $24 \%$ to $46 \%$ ) of the injected ${ }^{131} \mathrm{I}$ activity was recovered in the urine and in the second 24 hours $20^{\circ}$ (range $13^{\circ}$, to $28^{\circ}$ ) was recovered. With ${ }^{111}$ In labelled antibodies $10 \%$ (range $4.3 \%$ to $15 \%$ ) of the injected activity was recovered in the urine in the first 24 hours and $3 \%$ daily thereafter (up to seven days).

In patients given oral iodide and perchlorate neither ${ }^{131} \mathrm{I}$ nor ${ }^{99} \mathrm{~m} T \mathrm{Tc}$ accumulated in any organ except the bladder. In contrast, $20 \%$ of the injected dose of ${ }^{111}$ In accumulated in the liver and remained there for the duration of the study (eight days). This was the only organ significantly to accumulate ${ }^{111} \mathrm{In}$, and in particular there was little activity in the skeleton.

Whole body doses were the same for both isotopes, about $0 \cdot 135 \mathrm{mSv}$ (13.5 mrem)/MBq. Liver doses were $0.154 \mathrm{mSv} / \mathrm{MBq}$ for ${ }^{131}$ I-antiCEA administered, $0.783 \mathrm{mSv} / \mathrm{MBq}$ for ${ }^{111} \mathrm{In}$-anti-CEA, and 0.089 $\mathrm{mSv} / \mathrm{MBq}$ for ${ }^{99 \mathrm{~m}} \mathrm{Tc}$-colloid injected. Average bladder dose was $0.803 \mathrm{MSv} / \mathrm{MBq}$ from ${ }^{131} \mathrm{I}$. (Conversion: $1 \mathrm{~Sv}=100 \mathrm{rem}$.)

\section{Discussion}

These results show that ${ }^{111}$ In-anti-CEA detected more tumour sites and with greater certainty than did ${ }^{131}$ I-anti-CEA. Overall sensitivity of the ${ }^{131}$ I scans $(53 \%)$ was lower than in some reports, ${ }^{12}$ but this varies with the criteria used for staging. Furthermore, different groups of patients may not be comparable, and in our study comparisons were made within patients using the same dose of each isotope. The amount of isotope injected, however, was lower than used by some workers. ${ }^{1}$ One patient received $66 \mathrm{MBq}(1.8 \mathrm{mCi})$ but the others received between 18.5 and $27.7 \mathrm{MBq}(0 \cdot 5-0.75 \mathrm{mCi})$. Improved sensitivity was not shown simply by the excess of positive sites with ${ }^{111} \mathrm{In}$, but when lesions were detected by both isotopes ${ }^{111}$ In had more ++ scores, and when individual scans were compared the ${ }^{111}$ In counts reached higher statistical significance.

This improvement may largely be related to improved count rates. There was some improvement in ratios of tumour to normal tissue, which may reflect different in vivo handling of the two isotopes. Nevertheless, a clear distinction must be made between increased label in the tumour and a reduction in blood pool activity. Our results suggest that most accumulation occurs in the first 48 hours; but the label remains there, and further 
improvements in ratios are the result of blood clearance (see half life corrected figures in table II). This is in contrast with ${ }^{131} \mathrm{I}$, which is less stable in tumours, presumably due to internalisation and deiodination. ${ }^{12}$

On cursory inspection ${ }^{111}$ In might be thought to offer a great advantage over ${ }^{131} I$ in terms of dosimetry because of the absence of energetic $\beta^{-}$particles. ${ }^{111} \mathrm{In}$, however, produces several low energy $x$ rays and electrons which, combined with its longer biological half life, offset this advantage. Critical organ dose from ${ }^{111}$ In was to the liver, and from ${ }^{131}$ I to the bladder. We emphasise that the dosimetry calculation was based on a small excretion of ${ }^{111}$ In but a large excretion of ${ }^{131} I$ Since individual patients may vary widely in their rate of iodine excretion some may receive a higher dose from ${ }^{131} I$ than that calculated. In addition, it is important to ensure adequate blockade of the thyroid and stomach with iodide and perchlorate.

The doses used in our study were cautious, and the British Institute of Radiology guidelines ${ }^{18}$ would allow $300 \mathrm{MBq}$ $(8.1 \mathrm{mCi})$ of either isotope to be administered to such patients for clinical indications $(50 \mathrm{mSv}(5 \mathrm{rem})$ whole body and 250 $\mathrm{mSv}$ single organ). Radiation dose with computed tomography is about $10 \mathrm{mSv}$ ( $1 \mathrm{rem}$ ) per examination, and some other $x$ ray techniques, especially fluorography, give comparable doses.

With regard to detector efficiency and spatial resolution, our high energy collimator has an efficiency of $63 \%$ compared with the medium energy collimator. ${ }^{19}$ When counting only the 247 $\mathrm{keV}{ }^{111}$ In peak there is a detector efficiency factor of 3.2 in favour of ${ }^{111} \mathrm{In}$, reducing to 2.3 after 48 hours; if both ${ }^{111} \mathrm{In}$ peaks are included the factors are 7.8 and 5.6 respectively. Spatial resolution at $10 \mathrm{~cm}$ from the collimator face is $20 \mathrm{~mm}$ full width half maximum for ${ }^{131} \mathrm{I}$ and $17 \mathrm{~mm}$ full width half maximum for ${ }^{111} \operatorname{In} .{ }^{19}$

With regard to the antiserum, the total binding sites were not affected by either labelling procedure, but incorporating up to five molecules of DTPA had a measurable effect on affinity profile. The substitution is chemically similar to that employed with the Boulton and Hunter reagent, and damage might be expected to be related to the number of groups substituted per molecule of $\mathrm{IgG}^{7}$ Further refinements to the technique may enable reagents of equally high specific activity to be prepared without measurable effects on affinity, and, once synthesised, DTPA linked antibodies are easy to radiolabel. This has an advantage over iodination for a routine nuclear medicine department.

There have been several suggestions to improve antibody scans, of which increasing the number of counts emanating from the tumour is fundamental. ${ }^{20}$ Theoretical considerations and our results show that with ${ }^{111}$ In this is possible because of its physical characteristics and prolonged residence in tumours. This results in improved count rates and improved signal to noise ratios, which allow the detection of smaller or deeper lesions.

We thank Mr R Hawker for providing indium isotopes and useful discussion, Dr N Baggett for help with the chemical synthesis, and Dr R Flinn for help with computer analysis of the scans. S F WatsonJames is supported by a grant from the Endowment Fund of the Central Birmingham Health District, and D S Fairweather by a project grant from the CRC.

\section{References}

${ }^{1}$ Goldenberg DM, Deland F, Kim E, et al. Use of radiolabelled antibodies to carcinoembryonic antigen for the detection and localisation of diverse cancers by external scanning. N Engl f Med 1978;298:1384-8.

2 Fairweather DS, Bradwell AR, Watson-James SF, Dykes PW, Chandler S, Hoffenberg R. Detection of thyroid tumours using radio-labelled antithyroglobulin. Clin Endocrinol (Oxf) 1983;18:563-70.

${ }^{3}$ Goldenberg DM, Kim EE, Deland FH. Human chorionic gonadotrophin radioantibodies in the radioimmunodetection of cancer and the disclosure of occult metastases. Proc Natl Acad Sci USA 1981;78:7754-8.

4 Halsall AK, Fairweather DS, Bradwell AR, et al. Localisation of malignant germ-cell tumours by external scanning after injection of radiolabelled anti-alpha-fetoprotein. $B r M e d f 1981 ; 283$ :942-4.
${ }^{5}$ Fairweather DS, Bradwell AR, Dykes PW. Monoclonal antibodies for in vivo localisation. Lancet $1982 ;$ ii :660.

${ }^{6}$ Epentos AA, Britton KE, Mather S, et al. Targeting of iodine-123 labelled tumour-associated monoclonal antibodies to ovarian, breast, $\varrho$ and gastrointestinal tumours. Lancet 1982;ii:999-1006.

' Ecklman WC, Paik CH, Reba RC. Radiolabelling of antibodies. Cancer $\widehat{\widehat{\Omega}}$ Res $1980 ; 40: 3036-42$.

8 Thakur ML, Segal AW, Louis L, Welch MJ, Hopkins J, Peters J. J Indium-111-labelled cellular blood components: mechanism of labelling $\mathbb{D}$ and intracellular location in human neutrophils. $\mathcal{F ~} \mathrm{Nucl} \mathrm{Med} \mathrm{1977;18:}$ 1020-4.

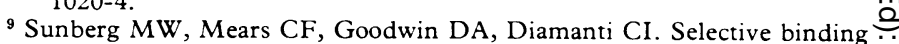
of metal ions to macromolecules using bifunctional analogs of EDTA. f Med Chem 1974;17:1304-7.

10 Wagner SJ, Welch MJ. Gallium-68 labelling of albumin and albumin $\overrightarrow{0}$ microspheres. F Nucl Med 1979;20:428-33.

11 Khaw BA, Fallon JT, Strauss HW, Harber E. Myocardial infarct imaging of antibodies to canine cardiac myosin with indium-11-diethylene $\frac{\rho}{7}$ triamine pentaacetic acid. Science $1980 ; \mathbf{2 0 9}: 295-7$.

12 Stern P, Hagan P, Halpern S, et al. The effect of the radiolabel on the kinetics of monoclonal anti-CEA in a nude mouse-human colon tumor $s$ model. In: Mitchel MS, Oettgen HF, eds. Hybridomas in cancer $\vec{\circ}$ diagnosis and treatment. New York: Raven Press, 1982:245-53.

13 Egan ML, Lautenschleger JE, Coligan JE, Todd CW. Radioimmune $\overrightarrow{\vec{H}}$ assay of carcinoembryonic antigen. Immunochemistry 1972;9:289-99.

${ }^{14}$ Krejcarek GE, Tucker KL. Covalent attachment of chelating groups to $\partial$ macromolecules. Biochem Biophys Res Comm 1977;77:581-5.

15 Watson-James SF, Fairweather DS, Bradwell AR. A shielded sterile apparatus for iodinating proteins. Med Lab Sci 1983;40:67-8.

${ }^{16}$ Snyder WS, Ford MR, Warner GG. Estimates of specific absorbed fractions for photon sources uniformly distributed in various organs of a heterogenous phantom. MIRD Pamphlet. No 5 (revised). New o York: Society of Nuclear Medicine, 1978.

17 Flemming JS. A technique for the absolute measurement of activity using $\vec{\sigma}$ a gamma camera and computer. Phys Med Biol 1979;24:176-80.

18 British Institute of Radiology. Guidelines. Irradiation of human subjects for medical research. Bulletin of the British Institute of Radiology 1975; No 1.

19 Anger HO, Davis DH. Gamma-ray detection efficiency and image

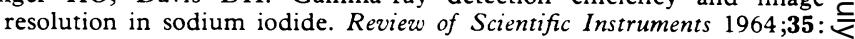
693-7.

${ }^{20}$ Rockoff SD, Goodenough DJ, McIntire KR. Theoretical limitations in $\vec{\varphi}$ the immunodiagnostic image of cancer with computed tomography and nuclear scanning. Cancer Res 1980;40:3054-8.

(Accepted 25 April 1983)

ONE HUNDRED YEARS AGO The police-courts have lately made public several instances of revolting cruelty suffered by little children in the course of their training for performance as acrobats. It appears that, in the present stage of our civilisation, the supply of acrobats is a steady public demand, and that many British children of $\delta$ very tender years are regularly devoted to the acrobatic business, to be systematically trained, while their limbs and joints are yielding, 0 by a long process of painful exercises enforced by punishment and $\frac{0}{\supset}$ privation, for the gratification of a debased public taste by their $\mathrm{N}$ performances as "human serpents," tumblers, and contortionists. $D$ Mr Charles Mylne Barker, who acted as honorary solicitor in the proceedings taken some time ago by Mr Littler, QC, and his friends, regarding a number of young English children found living in slavery, $\mathrm{O}$ or quasi-slavery, at Constantinople, writes to the Times to express his $\omega$ disappointment that a short Act of Parliament has not been passed $\widetilde{C}$ during the recent session, making it illegal for any infant child of twelve years of age or under to be apprenticed to any trade or business without the consent of a magistrate. Mr Barker states that, with the assistance of the authorities of the Criminal Investigation Department, he had made several inquiries as to the manner in which infant $\overline{0}$ children being trained as acrobats were treated when out of the $\overrightarrow{\mathbb{D}}$ jurisdiction of English courts ; and it was found that, in many instances, $\frac{\bigcirc}{\square}$

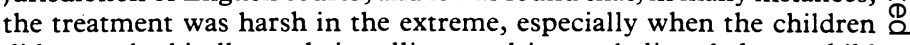
did not take kindly to their calling; and it was believed that a child $\sigma$ was actually killed in Spain, its back having been broken by the cruel treatment to which it was subjected. Mr Barker thinks that some o philanthropic member of Parliament, at a time when so much public sympathy is expended on the sufferings of pigeons, might have

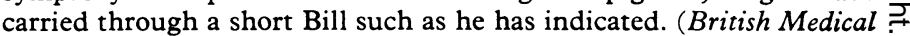
Fournal 1883 ;ii :440.) 